\title{
A Rare Case of Live Fish in Oropharynx and Its Management
}

\author{
${ }^{1}$ Suryakanta Pradhan, ${ }^{2}$ Sanjeev Gupta, ${ }^{3}$ Ambika P Dash, ${ }^{4}$ Jitendu Mohanty, ${ }^{5}$ Anup K Rana
}

\section{ABSTRACT}

Fish bone as foreign body in throat is very common in otorhinolaryngology practice. But a live fish in oropharynx is very rare. Small fishes, if ingested, can cross the oral cavity and migrate to esophagus, nasopharynx, or airway, but large fishes get impacted in the oropharynx. Most of these cases are life-threatening and require immediate intervention to save the patient.

Sometimes, tracheostomy is required to establish the airway and to remove the fish. We are reporting a case of live climbing perch (Anabas testudineus) which was successfully removed from the oropharynx of a 30 -year-old male without tracheostomy. We will mainly discuss the proper technique to remove live foreign bodies without causing any complications.

Keywords: Climbing perch, Live fish in oropharynx, Live foreign body, X-ray neck.

How to cite this article: Pradhan S, Gupta S, Dash AP, Mohanty J, Rana AK. A Rare Case of Live Fish in Oropharynx and Its Management. Int J Otorhinolaryngol Clin 2018;10(2):73-75.

Source of support: None

Conflict of interest: None

\section{CASE REPORT}

A 35-year-old male presented to the Emergency Department of Apollo Hospitals, Bhubaneswar, with pain, respiratory distress, and bleeding from the throat. History from the relatives suggested that one live fish had accidentally gone into his throat while fishing.

He was holding the fish near his mouth and was calling someone. Meantime, the fish wriggled and went straight into his mouth and got stuck in the throat. They first rushed to the nearest hospital where the doctors

\footnotetext{
${ }^{1}$ Junior Consultant, ${ }^{2,3}$ Senior Consultant, ${ }^{4}$ Consultant ${ }^{5}$ Emergency Physician

1,2Department of ENT-HNS, Apollo Hospitals, Bhubaneswar Orissa, India

${ }^{3}$ Department of General Surgery, Apollo Hospitals, Bhubaneswar Orissa, India

${ }^{4}$ Department of Anesthesiology, Apollo Hospitals, Bhubaneswar Orissa, India

${ }^{5}$ Department of Emergency Medicine, Apollo Hospitals Bhubaneswar, Orissa, India

Corresponding Author: Suryakanta Pradhan, Junior Consultant, Department of ENT-HNS, Apollo Hospitals Bhubaneswar, Orissa, India, e-mail: drsuryakanta83@gmail.com
}

tried to remove the fish in vain. He was later shifted to a medical college hospital where an X-ray was conducted before he decided to come to Apollo Hospitals.

On examination, there were lacerations inside the throat and some part of the tail of the fish was visible through the mouth. The movement of the fish made the pain acute and the patient was experiencing severe breathing difficulty and frequent coughing. He was even unable to talk. He was vomiting blood due to the movement of the fish causing more injury to the oropharynx. His oxygen saturation was decreasing (Fig. 1).

$X$-ray neck lateral view demonstrated that the head of the fish was stuck in the cricopharynx and the body was compressing the laryngeal inlet (Fig. 2). The patient

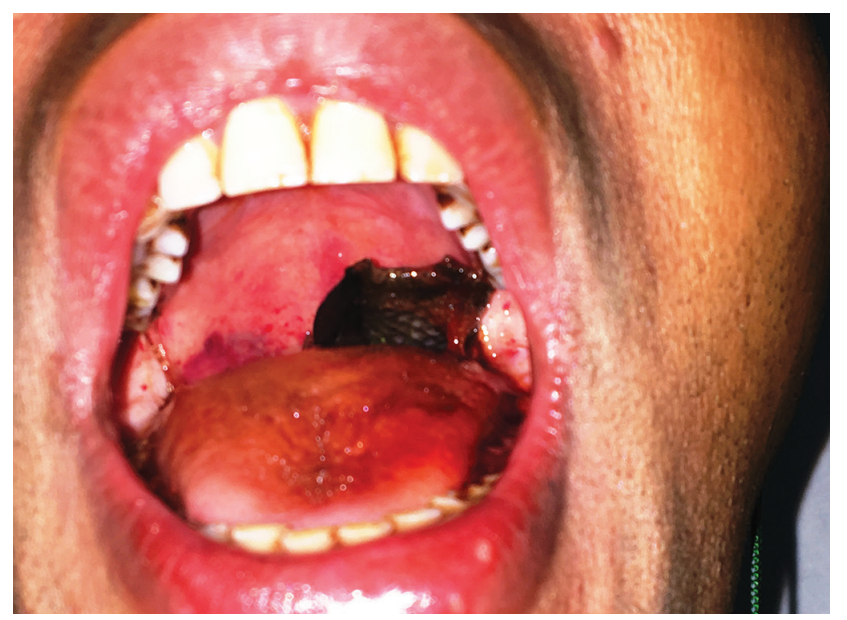

Fig. 1: Live fish in oropharynx. Only tail part of the fish is visible

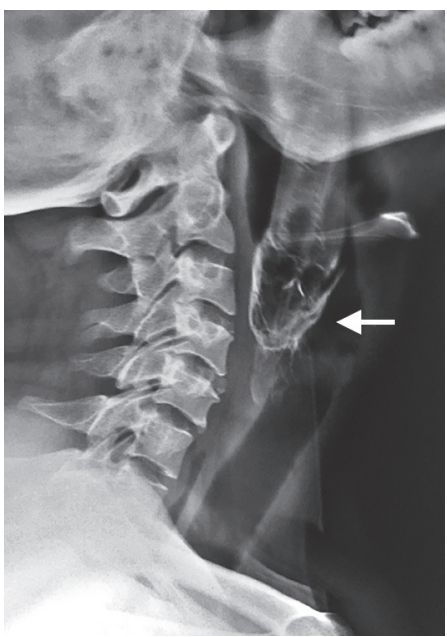

Fig. 2: X-ray neck lateral view. Arrow showing the head of fish impacted against the larynx 


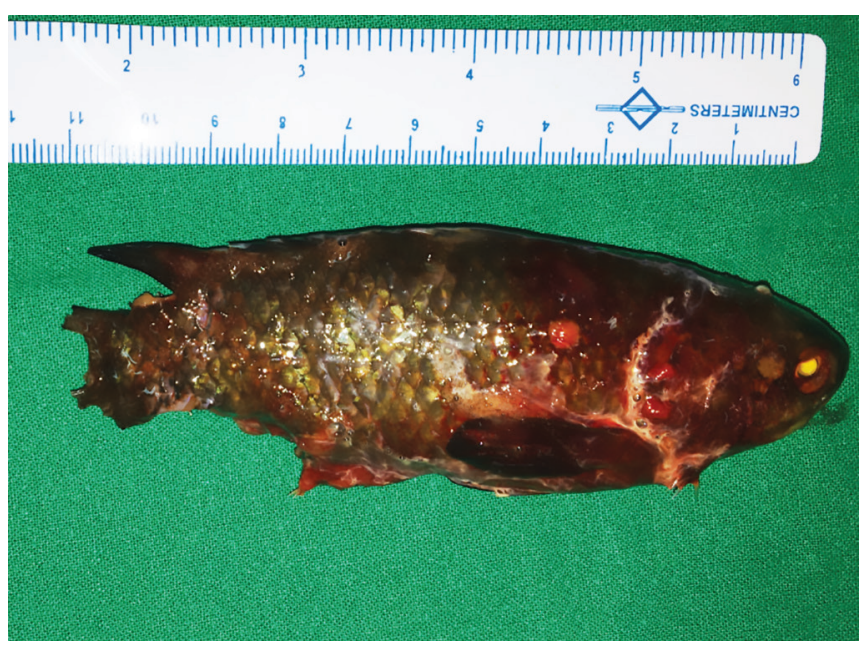

Fig. 3: Fish removed in toto

was immediately shifted to the emergency operation theater. Intravenous line was secured and injection Hydrocortisone $100 \mathrm{mg}$ i.v. was given to reduce the airway edema. We prepared the patient for tracheostomy under local anesthesia.

The patient was unable to lie down as there was severe pain and distress. In the sitting position, the local anesthetic spray was given. Mild sedation was given to relieve the anxiety. Boyle Davis mouth gag was applied. As only the tail was visible partially, we held it with the Allis forceps and applied gradual traction.

Then some more part of the fish was visible, which was grasped by a sponge holder. We continued the traction and the fish finally came out in one piece. After the removal, we examined the oropharynx and laryngopharynx with a direct laryngoscope for any remnant. It was severely lacerated, but there was no remnant. The length of the fish was $11 \mathrm{~cm}$ and the width was $4 \mathrm{~cm}$ (Fig. 3). The patient was relieved from pain and distress immediately after removal.

He was discharged under stable condition after 1 day of hospitalization. Ryle's tube was placed and feeding was given for 10 days. The tube was removed after 10 days and the lacerations were healed completely.

\section{DISCUSSION}

As an otorhinolaryngologist, we frequently encounter foreign bodies in aerodigestive tract.

One of the commonly seen foreign bodies is fish bone in throat. It may get lodged in tonsils, posterior pharyngeal wall, base of the tongue, valleculae, and larynx. However, a live fish in throat causing sever obstruction, pain, bleeding, and dyspnea is very rare. ${ }^{1}$

In the literature, different fishes were found in the aerodigestive tract, and the list includes Kio fish, Reef fish, Talapia fish, Lepomis macrochirus, and todi fish. ${ }^{2}$ No age group is spared from live fish ingestion. Starting from 7 months, ${ }^{3}$ it is reported till 65 years of age. ${ }^{4}$ The causes of ingestion of live fish are interesting. Mostly, fishermen bite one fish and make their hands free to catch another, the struggling fish escapes and gets stuck in the oropharynx. ${ }^{5}$

Some people swallow live fish as medicine for treatment of asthma, which accidentally gets embedded in the throat. The rarest cause is while taking bath, live fish can accidentally enter into the oropharynx. ${ }^{6}$ The site of lodgment of the fish depends on the shape and size. Small fishes can cross the larynx and reach the trachea or bronchus, but larger fishes can go up to the hypopharynx.

Sometimes, it may migrate upward and get impacted in the nasopharynx. ${ }^{6}$ In our case, the patient was catching fishes in his pond. He was holding the fish near his mouth which accidentally went inside. The fish was a climbing perch (A. testudineus) of $11 \mathrm{~cm}$ length and $4 \mathrm{~cm}$ breadth. They have special accessory respiratory organs which help these species to survive up to 6 days without water.

Climbing perch has very sharp fins over dorsal and ventral surfaces with the help of which they can crawl over the ground and climb trees. When ingested, they can cause severe trauma to the aerodigestive tract. It may lead to bleeding and respiratory distress. If it is lodged over the larynx, the patient may not manage to reach the hospital.

Sometimes, while removing from the oropharynx, it may slip and fall on the larynx causing obstruction. The complications due to live fish in aerodigestive tract include perforation of pharynx, mediastinitis, deep lacerations leading to secondary infection, remnant of sharp fins in the tissue, and death because of total obstruction. ${ }^{7}$

Sometimes, the lacerations may lead to retropharyngeal and parapharyngeal abscess which may present later and should be managed promptly. So it is always tricky to remove this type of foreign body, though the tail is visible. If nothing is visible, but history and examination indicate toward foreign body impaction, then radiology helps.

Patient should be advised for X-ray or computed tomography scan which will indicate the exact position of fish in the aerodigestive tract. But time should not be wasted in confirming the diagnosis if the patient is deteriorating. If there is suggestive history and symptoms of ingestion of foreign body, then patient should be immediately shifted to the operation theater and the foreign body should be taken away promptly.

Otherwise, it will be difficult to remove because of mucosal edema and injuries along with respiratory distress. ${ }^{5}$ In our case, we immediately shifted the patient to the operation theater, prepared for tracheostomy, and then tried to remove it. We gave local anesthetic spray and removed it in one piece and tracheostomy was avoided. 
In this scenario, the surgeon's expertise and technique of removal are important in decreasing the morbidity. Securing airway is the most important step and it should not be compromised. For this, most of the time, tracheostomy is required before removal of the fish. ${ }^{8}$ Sometimes, after tracheostomy, the patient will not be relieved from respiratory distress.

In those conditions, there should be a suspicion of fish in the nasopharynx, trachea, or bronchus. Then, bronchoscopy should be done to locate the foreign body and managed accordingly. After removal, the patient should be managed properly to avoid any delayed complications till complete recovery.

\section{CONCLUSION}

Live foreign bodies like fish in aerodigestive tract are very rare and life-threatening emergencies. The emergency team and peripheral doctors should be educated to resuscitate these types of patients and to do emergency tracheostomy and cricothyrotomy to secure the airway. The airway protection is the key while handling such patients.

After that, the patient should be promptly shifted to a center with all the facilities and skilled doctors to remove the foreign bodies. The patients should be followed up till complete recovery to avoid complications.

\section{CLINICAL SIGNIFICANCE}

This case summarizes the diagnosis and management of live foreign body in oropharynx which will develop awareness in health care personnel.

\section{REFERENCES}

1. Panigrahi R, Sarangi TR, Behera SK, Biswal RN. Unusual foreign body in throat. Indian J Otolaryngol Head Neck Surg 2007 Dec;59(4):384-385.

2. Saha KL, Talukder DC, Rasel MA, Saha A. Live fish in the trachea and bronchus: a case report. BMC Res Notes 2014 Sep 18;7:658.

3. Aggarwal MK, Singh GB, Dhawan R, Tiwari A. An unusual case of live fish impaction in hypopharynx in an infant. Int J Pediatr Otorhinolaryngol Extra 2006 Jun;1(2):154-156.

4. Ikenberry SO, Jue TL, Anderson MA, Appalaneni V, BanerjeeS, Ben-Menachem T, Decker GA, Fanelli RD, Fisher LR, Fukami $\mathrm{N}$, et al. Management of ingested FB and food impaction. Gastrointest Endosc 2011 Jun;73(6):1085-1091.

5. Mittal M, Yadav R, Mody N, Dhond PV. Live fish: unique foreign body throat. Bombay Hosp J 2011;53(4):804.

6. Parida PK, Surianarayanan G. Accidental entry of fish into throat while bathing in a pond. Case Rep Med 2013;2013: 604-687.

7. Pinheiro J, Cordeiro C, Vieira DN. Choking death on a live fish (Dicologoglossa cuneata). Am J Forensic Med Pathol 2003;24(2):177-178.

8. Tang ML, Ching LS, Brito Mutunayagam S, Revadi G. Fish in throat: an unusual foreign body. Med J Malaysia 2013 Dec;68(6):469-470 